\title{
PERFIL PEPTÍDICO DE HIDROLISADOS PROTÉICOS DA FARINHA DE TRIGO, APÓS A REMOÇÃO DE FENILALANINA
}

\section{PEPTIDE PROFILE OF PROTEIN HYDROLYSATES FROM WHEAT FLOUR AFTER PHENYLALANINE REMOVAL}

\author{
Raquel Linhares Carreira, Mauro Ramalho Silva, Viviane Dias Medeiros \\ Silva, Harriman Aley Morais, Marialice Pinto Coelho Silvestre
}

Universidade Federal de Minas Gerais e-mail: quelecia@gmail.com

Recebido para publicação em: 20/12/2009

Aceite para publicação em: 01/04/2010

\section{RESUMO}

Este trabalho teve como objetivo caracterizar o perfil peptídico de hidrolisados protéicos de farinha de trigo, após a remoção de fenilalanina. Inicialmente, as proteínas foram extraídas e hidrolisadas enzimaticamente, empregando-se a associação sucessiva de uma pancreatina comercial e de um extrato enzimático bruto obtido da casca de abacaxi (EB), preparado no laboratório. Em seguida, os hidrolisados protéicos foram tratados pelo carvão ativado para a remoção de fenilalanina e, então, fracionados por cromatografia líquida de alta eficiência de exclusão molecular, seguida pela quantificação dos peptídeos e aminoácidos livres pelo método da Área Corrigida da Fração. O efeito de alguns parâmetros hidrolíticos, tais como a ordem de adição das enzimas, a temperatura de reação, a relação enzima: substrato (E:S), foi avaliado, assim como o efeito do tratamento físico da amostra, visando, também, à redução de custos para a adaptação desse processo em larga escala. Foi observado que o emprego do ultraturrax no preparo da amostra foi benéfico, tendo produzido um menor teor de grandes peptídeos. Além disso, o conjunto dos resultados obtidos demonstrou a vantagem de se utilizar a pancreatina $(\mathrm{E}: \mathrm{S}=4: 100)$ primeiramente, por $3 \mathrm{~h} 30 \mathrm{~min}$, seguida da ação do $\mathrm{EB}$ $(\mathrm{E}: \mathrm{S}=10: 100)$ durante $1 \mathrm{~h} 30 \mathrm{~min}$, nas condições ótimas de $\mathrm{pH}$ e temperatura de cada enzima, produzindo uma maior quantidade de di-tripeptídeos $(23,58 \%)$, um dos maiores teores de aminoácidos livres $(36 \%)$ e o menor conteúdo de grandes peptídeos $(12 \%)$.

Palavras-chave: Farinha de trigo. Hidrolisados protéicos. Remoção de fenilalanina. Perfil peptídico. 


\begin{abstract}
The aim of this study was to characterize the peptide profile of wheat flour protein hydrolysates after the removal of phenylalanine. First, proteins were extracted and enzymatically hydrolyzed using successive association of a commercial pancreatin and a crude enzymatic extract (CE) of pineapple peel prepared in a laboratory. Next, protein hydrolysates were treated with activated carbon to remove phenylalanine and fractionated by size-exclusionHPLC followed by quantification of peptides and free amino acids by the Rapid Correct Fraction Area method. The effect of some hydrolytic parameters such as order of enzyme action, reaction temperature, enzyme: substrate ratio (E:S) and physical treatment of the sample was evaluated, considering also the reduction of costs for scaling-up the process. It was observed that the use of ultra-turrax for sample preparation was beneficial having produced low content of large peptides. In addition, the results showed the advantage of using firstly pancreatin $(\mathrm{E}: \mathrm{S}=$ 4:100) for $3 \mathrm{~h}: 30 \mathrm{~min}$ followed by CE (E:S =10:100) for $1 \mathrm{~h}: 30 \mathrm{~min}$, at optimal conditions of $\mathrm{pH}$ and temperature of each enzyme, reaching high amounts of ditripeptides $(23.58 \%), 36 \%$ of free amino acids and low content of larges peptides $(12 \%)$.
\end{abstract}

Keywords: Wheat flour. Protein hydrolysates. Phenylalanine removal. Peptide profile.

\section{INTRODUÇÃO}

A fenilcetonúria (PKU) consiste em uma patologia ocasionada por um erro inato do metabolismo, de herança autossômica recessiva (MARTINS et al., 1993), e que apresenta como principal tratamento uma dieta pobre em fenilalanina (Phe), devendo ser iniciada até o vigésimo primeiro dia de vida do recém-nascido e mantida por toda a vida (KANUFRE et al., 2001). Considerando que a Phe está presente em todas as proteínas de origem animal e vegetal na proporção de 3 a 6\% (OUTINEN et al., 1996), a redução de seus teores em alimentos representa uma etapa fundamental no desenvolvimento de produtos alimentícios para fenilcetonúricos, visto que o tratamento dessa patologia consiste, quase que exclusivamente, na utilização de misturas de aminoácidos livres que, no Brasil, são importadas e de elevado custo. Além disso, a ausência no mercado brasileiro de alimentos com teores reduzidos de Phe torna a dieta monótona, pouco atrativa e de difícil adesão (MIRA e MARQUEZ, 2000).

Os métodos utilizados para a remoção da Phe consistem em duas etapas principais: a liberação desse aminoácido por hidrólise enzimática e a sua posterior remoção por meios adsorventes diferenciados, como carvão ativado (CA) e resinas de adsorção. Para serem aplicados em larga escala, esses métodos devem ser práticos, de fácil reprodução, apresentar uma relação custo/benefício adequada, além de resultarem em produtos palatáveis (LOPEZBAJONERO et al., 1991; MOSZCZYNSKI e IDIZIAK, 1993). No mesmo laboratório do presente trabalho, o tratamento enzimático de proteínas, seguido da remoção pelo carvão ativado, vem sendo empregado para a remoção de Phe, tendo sido testadas diversas proteases e condições de hidrólise (MORATO et al., 2000; CARREIRA et al., 2004; LOPES et al., 2005; MORAIS et al., 2005; SILVA et al., 2007; SOARES et al., 2007), assim como avaliada a eficiência do CA na remoção de Phe de leite em pó desnatado (LOPES et al., 2006; SOARES et al., 2006), soro de leite (LOPES et al., 2007; SILVA et al., 2007), fubá de milho (CAPOBIANGO et al., 2007), arroz (LOPES et al., 2008), feijão (LOPES Jr. et al., 2010) e farinha de arroz (SILVESTRE et al., 2009).

Considerando a importância da farinha de trigo na alimentação do brasileiro e sua utilização restrita por parte dos fenilcetonúricos, é de grande interesse o desenvolvimento de uma farinha de trigo 
que contenha teor reduzido de fenilalanina, a fim de que possa ser incorporada, sem restrições, na dieta de fenilcetonúricos (NUPAD, 2008). Para a obtenção dessa farinha, seria necessária a associação de três etapas: inicialmente, a extração protéica, que é feita enzimaticamente, seguida da hidrólise protéica, empregando diferentes enzimas proteolíticas e condições de reação (CAPOBIANGO et al., 2007), o que promoveria a exposição da Phe, finalizando com sua posterior remoção pelo carvão ativado (LOPES et al., 2006, 2007; SOARES et al., 2006; CAPOBIANGO et al., 2007; SILVA et al., 2007; LOPES et al., 2008; SILVESTRE et al., 2009; LOPES Jr. et al., 2010).

Dessa forma, as proteínas hidrolisadas da farinha de trigo com baixo teor de fenilalanina e, ainda, com elevados teores de oligopeptídeos, o que as tornaria mais efetivamente absorvidas e utilizadas pelo organismo do que proteínas intactas e misturas de aminoácidos livres (KEOHANE et al., 1985; GRIMBLE et al., 1986; RÉRAT, 1993; BOZA et al., 2000), poderiam ser adicionadas ao amido (previamente separado na extração protéica), obtendo-se assim uma farinha de trigo a ser empregada na alimentação de crianças e adultos portadores de fenilcetonúria (KANUFRE et al., 2001).

Entretanto, o custo do processo de hidrólise protéica é elevado, devido, principalmente, ao emprego de proteases comerciais, normalmente importadas. Por isso, neste trabalho, foi testada a associação de uma enzima comercial com um extrato enzimático bruto, obtido de um resíduo agroindustrial (casca de abacaxi), preparado no laboratório.

O valor nutricional dos hidrolisados protéicos está relacionado diretamente com o seu alto teor de ditripeptídeos. Um método analítico que emprega uma coluna cromatográfica de exclusão molecular que contém o complexo poli (2-hidroxietil-aspartamida)sílica (PHEA) foi desenvolvido por Silvestre et al. (1994a), possibilitando-lhes fracionar e quantificar peptídeos com massas moleculares menores do que 1000 Da. Esse método já foi utilizado, pelo mesmo grupo de pesquisa, na caracterização do perfil peptídico de hidrolisados enzimáticos obtidos de diversas fontes protéicas (SILVESTRE et al., 1994b; MORATO et al., 2000; CARREIRA et al., 2004; LOPES et al., 2005; MORAIS et al., 2005; SOARES et al., 2006; LOPES et al., 2007; SILVA et al., 2007; LOPES et al., 2008; SOUZA et al., 2008).
Considerando que não foi encontrado na literatura qualquer relato sobre a caracterização do perfil peptídico de hidrolisados protéicos após a remoção de Phe, esse tema foi o objetivo principal do presente trabalho. Foi estudado, ainda, o efeito do tratamento físico da amostra, assim como do emprego da associação sucessiva de uma pancreatina comercial com o extrato enzimático bruto da casca de abacaxi (EB), preparado no laboratório, tendo sido avaliada a ação de alguns parâmetros hidrolíticos, tais como a ordem de adição das enzimas, a relação E:S e a temperatura de reação.

\section{MATERIAL E MÉTODOS}

\subsection{Material}

A farinha de trigo tipo I foi adquirida no comércio de Belo Horizonte, MG. A protease Protemax ${ }^{\circledR}$ 580 L (EC 3.4.21.14), uma serino-endopeptidase de origem bacteriana - cepa do Bacillus licheniformis, atividade $580 \mathrm{KDU} / \mathrm{g}$, estável em pH entre 7 e 10 com pH ótimo em 9,5 , temperatura ótima de $60^{\circ} \mathrm{Ce}$ temperatura de inativação acima de $85^{\circ} \mathrm{C}$ por $10 \mathrm{~min}$ ), foi adquirida da Prozyn (São Paulo, SP, Brasil). A pancreatina (Corolase ${ }^{\circledR} \mathrm{PP}$ ) (complexo enzimático obtido do pâncreas (EC 3.4.21.4), constituído pelas serina-endopeptidases tripsina e quimotripsina, e pelas metalo-exopeptidases carboxipeptidases A e $\mathrm{B}$, atividade $200.000 \mathrm{LVE} / \mathrm{g}, \mathrm{pH}$ ótimo de 9 e temperatura ótima de $50{ }^{\circ} \mathrm{C}$ ) foi adquirida da $\mathrm{AB}$ Enzymes Brasil Comercial Ltda. (Barueri, SP, Brasil). Os aminoácidos L-fenilalanina, L-tirosina e Ltriptofano foram adquiridos da Sigma-Aldrich (St. Louis, MO, EUA). O carvão ativado (granulado ${ }^{\circ}$ 119, 20 × 50 mesh, 12 × 25 mesh, $6 \times 12$ mesh) foi adquirido da Carbomafra S.A. (Curitiba, PR, Brasil). O extrato enzimático bruto da casca do abacaxi (Ananás comosus) variedade Pérola, foi preparado no laboratório. Foram utilizados o Liofilizador Freezone (modelo 77500, Labconco, Kansas City, MI, EUA), o compressor (Diapump, Fanem, mod. 089-A, série BE11778, São Paulo, SP, Brasil), o cutter (Sire, modelo Super Cutter, São Paulo, Brasil), o ultraturrax (IKA Labortechnix, T25 basic, Wilmington, EUA) e o agitador magnético (Fisatom, modelo 752 A, São Paulo, SP, Brasil). O sistema de cromatografia líquida 
de alta eficiência de exclusão molecular (SE-HPLC), usado no fracionamento dos hidrolisados protéicos, foi constituído por uma coluna cromatográfica poli-(2-hidroxietil-aspartamida)-silica (PHEA) 250 x 9,4 mm, $5 \mu \mathrm{m}$ e $200 \AA$ (PolylC, Columbia, MD, EUA), uma bomba isocrática e um detector espectrofotométrico UV-VIS (série HP1100, Waldbronn, Alemanha), acoplado a um computador com software (HPchemstation, Avondale, EUA). A água usada no cromatógrafo foi purificada em Sistema de Purificação (Áries Vaponics, Rockland, EUA). Todos os reagentes utilizados eram de grau analítico.

\subsection{Métodos}

\subsubsection{Preparo dos hidrolisados protéicos da farinha de trigo}

Inicialmente, as proteínas da farinha de trigo foram extraídas empregando-se o método enzimático desenvolvido pelo mesmo grupo do presente trabalho (CAPOBIANGO et al., 2007). Em seguida, as proteínas foram hidrolisadas enzimaticamente, tendo sido obtidos nove hidrolisados protéicos (Tabela 1). Foi testada, assim, a associação sucessiva da pancreatina comercial com o extrato enzimático bruto da casca de abacaxi - EB, preparado no laboratório onde foi desenvolvido este estudo, variando os parâmetros: ordem de adição das enzimas (pancreatina + EB e $\mathrm{EB}+$ pancreatina); temperatura $\left(35,40,50\right.$ e $\left.70{ }^{\circ} \mathrm{C}\right)$, relação enzima:substrato (E:S) $(2: 100,3: 100$ e 4:100) para a pancreatina. $\mathrm{O}$ efeito do tratamento físico foi testado para apenas uma das amostras. O tempo total de reação, para todas as amostras, foi de cinco horas.

Tabela 1 - Variáveis empregadas no preparo dos hidrolisados protéicos da farinha de trigo

\begin{tabular}{|c|c|c|c|c|c|c|}
\hline \multicolumn{6}{|c|}{ Parâmetros Hidrolíticos } & \multirow[b]{2}{*}{$\mathrm{Te}$} \\
\hline $\mathrm{H}$ & Protease & $\mathrm{E}: \mathrm{S}$ & $\mathrm{T}\left({ }^{\circ} \mathrm{C}\right)$ & Tempo (h) & $\mathrm{pH}$ & \\
\hline H1 & $\mathrm{EB}+$ pancreatina & $10: 100+4: 100$ & $70 / 50$ & $1 \mathrm{~h} 30 \mathrm{~min} / 3 \mathrm{~h} 30 \mathrm{~min}$ & $8 / 7$ & Ausente \\
\hline $\mathrm{H} 2$ & Pancreatina + EB & $4: 100+10: 100$ & $50 / 70$ & $3 \mathrm{~h} 30 \mathrm{~min} / 1 \mathrm{~h} 30 \mathrm{~min}$ & $7 / 8$ & Ausente \\
\hline H3 & $\mathrm{EB}+$ pancreatina & $10: 100+4: 100$ & 35 & $1 \mathrm{~h} 30 \mathrm{~min} / 3 \mathrm{~h} 30 \mathrm{~min}$ & 7 & Ausente \\
\hline $\mathrm{H} 4$ & $\mathrm{~EB}+$ pancreatina & $10: 100+4: 100$ & 40 & $1 \mathrm{~h} 30 \mathrm{~min} / 3 \mathrm{~h} 30 \mathrm{~min}$ & 7 & Ausente \\
\hline H5 & $\mathrm{EB}+$ pancreatina & $10: 100+4: 100$ & 50 & $1 \mathrm{~h} 30 \mathrm{~min} / 3 \mathrm{~h} 30 \mathrm{~min}$ & 7 & Ausente \\
\hline H6 & $\mathrm{EB}+$ pancreatina & $10: 100+4: 100$ & 70 & $1 \mathrm{~h} 30 \mathrm{~min} / 3 \mathrm{~h} 30 \mathrm{~min}$ & 7 & Ausente \\
\hline H7 & $\mathrm{EB}+$ pancreatina & $10: 100+2: 100$ & 50 & $1 \mathrm{~h} 30 \mathrm{~min} / 3 \mathrm{~h} 30 \mathrm{~min}$ & 7 & Ausente \\
\hline H8 & $\mathrm{EB}+$ pancreatina & $10: 100+3: 100$ & 50 & $1 \mathrm{~h} 30 \mathrm{~min} / 3 \mathrm{~h} 30 \mathrm{~min}$ & 7 & Ausente \\
\hline H9 & $\mathrm{EB}+$ pancreatina & $10: 100+3: 100$ & 50 & $1 \mathrm{~h} 30 \mathrm{~min} / 3 \mathrm{~h} 30 \mathrm{~min}$ & 7 & Ultraturrax \\
\hline
\end{tabular}

$\mathrm{H}$ = hidrolisado; EB: extrato enzimático bruto da casca de abacaxi; E:S: relação enzima:substrato; $\mathrm{T}=$ temperatura; Te: tratamento físico do extrato.

\subsubsection{Remoção de fenilalanina dos hidrolisados protéicos}

A Phe foi removida dos hidrolisados protéicos da farinha de trigo pela utilização do carvão ativado (CA) como meio adsorvente, usando-se a relação proteína:carvão ativado 1:88,5 - utilizada, anterior- mente, no mesmo laboratório deste trabalho (CAPOBIANGO et al., 2007; SILVESTRE et al., 2009). Foi empregado o procedimento de passagem por coluna, descrito nesse mesmo laboratório por Soares et al. (2006). Dois gramas de CA de granulometrias diferentes ( 20 × 50 mesh, 12 × 25 mesh e $6 \times 12$ mesh) foram hidratados com água destilada por $10 \mathrm{~min}$ sob 
agitação constante e, em seguida, colocados em seringa descartável de $10 \mathrm{~mL}$, contendo filtro de nylon com lã de vidro. Em seguida, os hidrolisados foram passados pela coluna e submetidos à pressão, tendo sido recolhidos os eluatos.

\subsubsection{Caracterização do perfil peptídico dos hidrolisados protéicos}

A caracterização do perfil peptídico dos hidrolisados, após a remoção de fenilalanina, foi realizada em duas etapas: fracionamento dos peptídeos, de acordo com o tamanho da cadeia, e sua posterior quantificação. $\mathrm{O}$ fracionamento dos peptídeos foi realizado por cromatografia líquida de alta eficiência de exclusão molecular (SE-HPLC) em coluna PHEA, conforme descrito por Silvestre et al. (1994a). As amostras foram dissolvidas em uma concentração de $1 \mathrm{~g} \%(\mathrm{p} / \mathrm{v})$ na fase móvel (ácido fórmico a 0,05 mol L-1, pH 2,5) e submetidas à cromatografia à temperatura ambiente, sob condições isocráticas, a

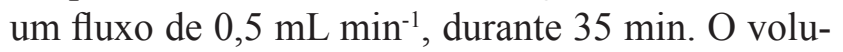
me injetado foi de $20 \mu \mathrm{L}$. A fase móvel foi filtrada, através da membrana de 0,45 $\mu \mathrm{m}$ (Millipore, São Paulo, SP, Brasil) e desgaseificada imediatamente antes do uso.

O método rápido da Área Corrigida da Fração (ACF), desenvolvido por Silvestre et al. (1994b), foi utilizado para quantificar os peptídeos e aminoácidos livres presentes nas frações cromatográficas. O cálculo da ACF foi realizado após a multidetecção das frações a $230 \mathrm{~nm}, 280 \mathrm{~nm}$ e $300 \mathrm{~nm}$, para se eliminar a interferência devida à absorção dos aminoácidos aromáticos. Foi traçada, então, uma curva padrão, relacionando a ACF em função do teor de aminoácidos.

\subsection{Análise Estatística}

Todos os experimentos foram feitos em três repetições e as análises realizadas em triplicata. Os dados foram submetidos à análise de variância e, para a avaliação das diferenças entre as médias dos teores de peptídeos e aminoácidos livres das frações cromatográficas dos hidrolisados protéicos, foi utilizado o Teste de Duncan $(\mathrm{p} \leq 0,05)$ (PIMENTEL-GOMES, 2000).

\section{RESULTADOS E DISCUSSÃO}

\subsection{Caracterização dos hidrolisados protéicos}

\subsubsection{Perfil peptídico}

O perfil cromatográfico do hidrolisado $\mathrm{H} 1$, a 230 nm, está apresentado na Figura I.1. Como pode ser observado, os hidrolisados foram separados em quatro frações de acordo com o tempo de eluição, sendo F1, de 11,5 a 16,0 min (grandes peptídeos, com mais de 7 resíduos de aminoácidos); F2, de 16,0 a 19,5 min (peptídeos médios, entre 4 e 7 resíduos); F3, de 19,5 a 20,5 min (di-tripeptídeos); e F4, de 20,5 a 32,0 min (aminoácidos livres), confirmando, assim, a eficiência da técnica aqui empregada (SE-HPLC) para fracionar os hidrolisados protéicos com massas moleculares inferiores a 1000 Da. Esses resultados estão de acordo com os obtidos em estudos anteriores realizados nesse mesmo laboratório, empregando-se essa mesma metodologia para caracterizar os hidrolisados de diferentes fontes protéicas, tais como o soro de leite (LOPES et al., 2007; SILVA et al., 2007; SOUZA et al., 2008), a caseína (MORATO et al., 2000; BARBOSA et al., 2004; CARREIRA et al., 2004; MORAIS et al., 2005), o leite (LOPES et al., 2005; SOARES et al., 2006) e o arroz (LOPES et al., 2008).

Figura 1 - Perfil cromatográfico do hidrolisado H1 a $230 \mathrm{~nm}$.

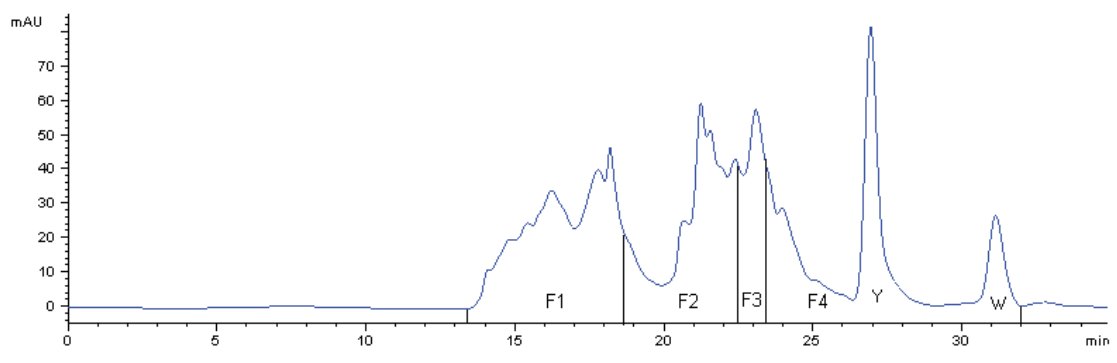

F1: grandes peptídeos ( $>7$ resíduos de aminoácidos); F2: médios peptídeos (4 a 7 resíduos de aminoácidos); F3: di-tripeptídeos; F4: aminoácidos livres. $\mathrm{Y}=$ pico da tirosina, $\mathrm{W}=$ pico do triptofano. Hidrolisado H1: $\mathrm{EB}\left(10: 100,70^{\circ} \mathrm{C}, 1 \mathrm{~h} 30 \mathrm{~min}, \mathrm{pH} 8,0\right)+$ pancreatina $(4: 100$, $\left.70{ }^{\circ} \mathrm{C}, 3 \mathrm{~h} 30 \mathrm{~min}, \mathrm{pH} 7,0\right)$. 
O fracionamento dos peptídeos de hidrolisados protéicos pode ser realizado através de diversas técnicas, como, por exemplo, eletroforese em gel de poliacrilamida dodecil sulfato de sódio (SDS-PAGE) (CHICÓN et al., 2009), cromatografia de exclusão molecular (SEC) (LI-JUN et al., 2008), cromatografia líquida de alta velocidade com eletrospray acoplado ao espectrômetro de massa (LI-JUN et al., 2008), HPLC capilar (ITO et al., 2005), HPLC de fase reversa (NOGUEIRA et al., 2005), HPLC de exclusão molecular (SE-HPLC) empregando coluna TSK G-2000 SW $(6 \times 7,5 \mathrm{~cm})($ LEMIEUX et al., 1991) e coluna Superose - 12HR 10/30 (GOLOVCHENKO et al., 1992; VISSER et al., 1992), cromatografia rápida de fase líquida de proteína (Fast protein liquid chromatography - FPLC) (JE et al., 2007) e foco isoelétrico em fase líquida (SAINT-SAUVEUR et al., 2008).

Porém, diferentemente do que acontece com a metodologia utilizada no presente trabalho, muitos autores têm relatado alguns problemas com as outras técnicas analíticas. Assim, Lemieux et al. (1991), empregando a SE-HPLC com uma coluna TSK G-2000 SW, e Davis e Lee (1992), empregando a HPLC capilar, relataram a dificuldade de separar os peptídeos de acordo com o tamanho da cadeia, tendo observado uma superposição de compostos com pesos moleculares diferentes. De acordo com Nogueira et al. (2005), na HPLC de fase reversa há sobreposição de peptídeos e impureza nos picos. Além disso, também pode ocorrer sobrecarga de peptídeos básicos tanto na HPLC de fase reversa quanto na HPLC capilar (McCALLEY, 2004).

Golovchenko et al. (1992) e VIisser et al. (1992), também utilizando SE-HPLC, porém com uma coluna Superose -12HR 10/30, verificaram a ocorrência de interações eletrostáticas e/ ou hidrofóbicas entre os solutos e a fase estacionária. Schmidt e Poll (1991), empregando a SDS-PAGE, relataram a dificuldade de detectar pequenos peptídeos $(<2000 \mathrm{Da})$ pela técnica utilizada, uma vez que os peptídeos, devido à fixação insuficiente, são removidos durante os procedimentos de revelação e lavagem do gel.

A SE-HPLC também foi empregada para caracterizar o perfil peptídico dos hidrolisados de glúten do trigo; entretanto, os resultados encontrados demonstraram que não foi possível separar os ditripeptídeos dos peptídeos maiores. Assim, Wang et al. (2007), ao analisarem os hidrolisados de glúten do trigo obtidos com o uso de uma papaína, empregando a SE-HPLC com a coluna BioSepSec-4000, separaram os peptídeos obtidos nas seguintes frações: maiores que 15.000 Da, entre 15-10.000 Da, entre 5-10.000 Da e menores que 5.000 Da. De forma semelhante, Kong et al. (2007), ao avaliarem a distribuição da massa molecular dos peptídeos obtidos da hidrólise do glúten do trigo, sob ação das enzimas proteolíticas alcalase (Bacillus licheniformis) e neutrase (Bacillus amyloliquefaciens), empregando a SE -HPLC com a coluna Sephadex G-15, observaram apenas que os peptídeos apresentavam massa molecular inferior a $1355 \mathrm{Da}$, não sendo avaliado em separado o conteúdo de di-tripeptídeos.

Outra aplicação da técnica do fracionamento por SE-HPLC consistiu na avaliação do perfil peptídico de hidrolisados protéicos de farinha de trigo. Assim, Akiyama et al. (2006) empregaram esse método cromatográfico com a coluna Superdex ${ }^{\mathrm{TM}}$ Peptide HR, com o intuito de separar as frações dos hidrolisados ácido e enzimático. Entretanto, esse método não foi capaz de fracionar os peptídeos, de acordo com o tamanho da cadeia, especialmente os pequenos peptídeos. Segundo os autores, apenas a faixa de massa molecular foi evidenciada, sendo que no hidrolisado preparado sob a ação de protease predominaram os peptídeos com massa molecular superior a 1.050.000 Da, enquanto que os peptídeos obtidos no hidrolisado ácido ficaram na faixa de 500-1.050.000 Da. Manu e Rao (2008) fracionaram por SE-HPLC com a coluna Biosep-SEC-S-4000 os extratos protéicos alcançados a partir de diferentes cultivares de farinha de trigo, obtendo as frações F1 (>130.000 Da), F2 (80 $-130.000 \mathrm{Da}), \mathrm{F} 3(10-80.000 \mathrm{Da})$ e F4 (<5.000 Da), sendo esses valores superiores aos determinados no presente estudo. Da mesma maneira, Kammoun et al. (2003) utilizaram a SE-HPLC e a coluna Shodex KW 802.5 para caracterizar o perfil peptídico do hidrolisado de farinha de trigo, obtido pela ação da enzima Neutrase (endoprotease de Bacillus subtilis), obtendo também quatro frações: Fração1 (0-1.000 Da), Fração 2 (1-2.000 Da), Fração 3 (2-3.000 Da) e Fração $4(>3.000 \mathrm{Da})$, estando apenas a Fração 1 dentro da faixa de massa molecular de principal interesse do presente trabalho.

Não foram encontrados na literatura trabalhos que avaliaram o perfil peptídico de hidrolisados 
protéicos de farinha de trigo ou de outros cereais, após a remoção de Phe.

\subsubsection{Teor de peptídeos e de aminoácidos livres}

Os teores dos peptídeos constituintes das frações cromatográficas dos hidrolisados de farinha de trigo estão apresentados na Tabela 2. Com exceção do hidrolisado H2, não houve uma grande variação entre os perfis peptídicos das amostras analisadas. Além disso, os elevados teores de di-tripeptídeos e aminoácidos livres obtidos, associados a quantidades relativamente baixas de grandes peptídeos, comprovam a qualidade nutricional para todos os hidrolisados estudados, uma vez que, em outros trabalhos realizados, anteriormente, no Laboratório de Bromatologia/Pesquisa, testando várias fontes protéicas e diferentes condições hidrolíticas, ficou evidenciada a dificuldade de se obter teores de di-tripeptídeos acima de $10 \%$, de aminoácidos livres acima de 30\% e de grandes peptídeos abaixo de 25\% (MORATO et al., 2000; BARBOSA et al., 2004; CARREIRA et al., 2004; LOPES et al., 2005; MORAIS et al., 2005; SOARES et al., 2006; LOPES et al., 2007; SILVA et al., 2007; LOPES et al., 2008; SOUZA et al., 2008). Esses valores somente foram mais elevados após a utilização da ultrafiltração, visando à retirada de peptídeos com massa molecular superior a $10.000 \mathrm{Da}$ (LOPES et al., 2007).

Apesar destas considerações iniciais, a escolha do hidrolisado que apresentou o melhor perfil peptídico, do ponto de vista nutricional, deve ser amparada, também, em observações de outros autores. Assim, segundo Frenhani e Burini (1999), durante o metabolismo de proteínas, o primeiro estágio de hidrólise leva à formação de oligopeptídeos contendo de 2 a 6 resíduos de aminoácidos e aminoácidos livres. Esses peptídeos são, então, quebrados em di-tripeptídeos e, finalmente, as proteínas são absorvidas na forma de di-tripeptídeos e de aminoácidos livres. Ainda, de acordo com esses mesmos autores, os di-tripeptídeos são mais eficientemente absorvidos que os aminoácidos livres, os quais, por sua vez, são melhores que os tetra- ou peptídeos superiores. Em quantidades equivalentes de di-tripeptídeos e misturas de aminoácidos livres, os di-tripeptídeos apresentam velocidade de absorção aproximadamente dez vezes maior. González-Tello et al. (1994) também relatam as vantagens dos di-tripeptídeos sobre os aminoácidos livres por apresentarem maior velocidade de absorção.

Assim sendo, do ponto de vista nutricional, o hidrolisado $\mathrm{H} 2$ apresentou o melhor perfil peptídico, com um dos maiores teores de di-tripeptídeos (23,58\%) e de aminoácidos livres (36\%), e o menor teor de grandes peptídeos (12\%). Por outro lado, os perfis peptídicos mais desfavoráveis foram obtidos para os hidrolisados H1, H6 e H7, pois, apesar dos seus teores de di-tripeptídeos e de aminoácidos livres se situarem entre os mais elevados, os valores encontrados para os grandes peptídeos foram os maiores $(20,47 \%, 20,92 \%$ e $23,13 \%$, respectivamente).

Tabela 2 - Teor de peptídeos e de aminoácidos livres nas frações cromatográficas dos hidrolisados protéicos

\begin{tabular}{c|c|c|c|c}
\hline Hidrolisado & Fração F1 & Fração F2 & Fração F3 & Fração F4 \\
\hline H1 & $20,47^{\mathrm{a}, \mathrm{b}, \mathrm{c} / 3}$ & $27,81^{\mathrm{b} / 2}$ & $14,97^{\mathrm{b} / 4}$ & $36,75^{\mathrm{a}, \mathrm{b} / 1}$ \\
\hline $\mathrm{H} 2$ & $12,00^{\mathrm{f} / 4}$ & $28,43^{\mathrm{b} / 2}$ & $23,58^{\mathrm{a} / 3}$ & $36,00^{\mathrm{a}, \mathrm{b} / 1}$ \\
\hline $\mathrm{H} 3$ & $19,18^{\mathrm{b}, \mathrm{c}, \mathrm{d}, \mathrm{e} / 3}$ & $30,26^{\mathrm{a}, \mathrm{b} / 2}$ & $15,50^{\mathrm{b} / 4}$ & $35,06^{\mathrm{b} / 1}$ \\
\hline $\mathrm{H} 4$ & $16,64^{\mathrm{d}, \mathrm{e} / 3}$ & $32,69^{\mathrm{a} / 1}$ & $22,28^{\mathrm{a} / 2}$ & $28,40^{\mathrm{c} / 1}$ \\
\hline $\mathrm{H} 5$ & $17,98^{\mathrm{c}, \mathrm{d}, \mathrm{e} / 3}$ & $29,18^{\mathrm{a}, \mathrm{b} / 2}$ & $15,24^{\mathrm{b} / 3}$ & $37,60^{\mathrm{a}, \mathrm{b} / 1}$ \\
\hline H6 & $20,92^{\mathrm{a}, \mathrm{b} / 3}$ & $27,02^{\mathrm{b} / 1}$ & $14,34^{\mathrm{b} / 4}$ & $34,39^{\mathrm{b} / 2}$ \\
\hline H8 & $23,13^{\mathrm{a} / 2}$ & $26,18^{\mathrm{b} / 2}$ & $14,56^{\mathrm{b} / 3}$ & $36,14^{\mathrm{a}, \mathrm{b} / 1}$ \\
\hline H9 & $19,38^{\mathrm{b}, \mathrm{c}, \mathrm{d} / 3}$ & $27,38^{\mathrm{b} / 2}$ & $13,81^{\mathrm{b} / 4}$ & $39,43^{\mathrm{a}, \mathrm{b} / 1}$ \\
\hline
\end{tabular}

Todos os valores são apresentados em \% nmols das quatro frações. Os resultados representam a média das triplicatas. Médias indicadas por números iguais não diferem entre si a 5\% de significância na comparação de diferentes frações de um mesmo hidrolisado (linha). Médias indicadas por letras iguais não diferem entre si a 5\% de significância na comparação de uma mesma fração para diferentes hidrolisados (coluna). F1: maior que 7 resíduos de aminoácidos; F2: entre 4 e 7 resíduos; F3: di-tripeptídeos e F4: aminoácidos livres. 


\subsection{Efeito de parâmetros sobre o perfil peptídico dos hidrolisados protéicos}

Os parâmetros (E:S, temperatura e emprego do ultraturrax) utilizados neste trabalho foram analisados considerando a aplicabilidade do processo em larga escala e a redução dos gastos envolvidos. Assim, o emprego de uma menor relação E:S está associado à utilização de menor quantidade de enzima necessária para a hidrólise; o de uma menor temperatura de reação está associado à diminuição de contaminação bacteriana, à redução de formação de produtos de degradação, além de menor consumo de energia, sendo este último fator também associado à necessidade da eliminação da etapa operacional do ultraturrax.

\subsubsection{Ordem de adição das enzimas}

A ordem de adição das enzimas (EB + pancreatina e pancreatina + EB), empregada em associação sucessiva, interferiu no perfil peptídico dos hidrolisados protéicos de farinha de trigo. Como pode ser observado na Tabela I.2, a melhor distribuição de peptídeos foi obtida quando a pancreatina atuou primeiro, uma vez que promoveu um maior teor de di-tripeptídeos (H2 - 23,58\% e H1 - 14,97\%) e uma menor quantidade de grandes peptídeos (H2 $12,00 \%$ e H1 - 20,47\%). Por outro lado, não houve diferença significativa entre os teores de aminoácidos livres $(36,75 \%$ e $36 \%$, para $\mathrm{H} 1$ e $\mathrm{H} 2$, respectivamente). Esses resultados eram esperados teoricamente, baseando-se no conhecimento do complexo enzimático da pancreatina. Assim sendo, suas subunidades endopeptidases (tripsina e quimotripsina) e as exopeptidases (carboxipeptidase A e B), ao atuarem primeiro, promoveriam a hidrólise das ligações peptídicas internas e as presentes nas porções $\mathrm{N}$ - ou Cterminais da cadeia peptídica, facilitando o posterior acesso do EB, que, por apresentar, provavelmente, atividade predominante de exopeptidase, atuaria, principalmente, na porção terminal dos peptídeos previamente liberados.

Não foram encontrados na literatura relatos abordando o efeito da ordem de adição das enzimas sobre o perfil peptídico de hidrolisados protéicos da farinha de trigo ou de outros cereais, após a remoção de fenilalanina.

\subsubsection{Temperatura de reação}

Para a avaliação deste parâmetro, foram comparados os resultados obtidos para os hidrolisados $\mathrm{H} 3\left(35^{\circ} \mathrm{C}\right), \mathrm{H} 4\left(40^{\circ} \mathrm{C}\right), \mathrm{H} 5\left(50^{\circ} \mathrm{C}\right)$ e H6 $\left(70{ }^{\circ} \mathrm{C}\right)$, apresentados na Tabela I.2. Do ponto de vista nutricional, o melhor perfil peptídico foi obtido a $40{ }^{\circ} \mathrm{C}$. Além disso, o emprego vantajoso de uma menor temperatura ocorreu ao se comparar os valores de $40{ }^{\circ} \mathrm{C}$ (H5) e $70^{\circ} \mathrm{C}$ (H6), pois, apesar da redução nos teores de aminoácidos livres $(28,40 \%$ e $34,39 \%$, para H4 e H6, respectivamente), o emprego da temperatura mais baixa levou à obtenção de teores mais elevados de di-tripeptídeos (22,28\% em H4 e 14,34\% em H6) e de menor quantidade de grandes peptídeos $(16,64 \%$ e $20,92 \%$, para $\mathrm{H} 4$ e H6, respectivamente).

Apesar da temperatura de $40{ }^{\circ} \mathrm{C}$ não corresponder ao ótimo de ação de nenhuma das duas enzimas utilizadas no processo hidrolítico, esse valor se encontra próximo à temperatura ótima de ação da pancreatina $\left(50^{\circ} \mathrm{C}\right)$, o que, provavelmente, poderia ter contribuído para intensificar a sua atividade proteolítica, explicando, pelo menos parcialmente, o resultado obtido. Além disso, o emprego de elevadas temperaturas ocasiona a formação de estados de transição de energia, sendo esse processo acompanhado de uma pequena, mas significativa desordem no sítio ativo da enzima, o que promove uma ruptura das principais ligações que estabilizam a estrutura nativa da proteína e compromete sua capacidade hidrolítica (ARROYO-REYNA e HERNANDEZ-ARANA, 1995). Deve ser ressaltado, ainda, que, se por um lado o emprego de temperaturas mais elevadas aumenta o rendimento das reações enzimáticas, por outro pode provocar a inativação da enzima, comprometendo o processo de hidrólise (FENNEMA, 1996). Esses resultados também estão de acordo com Loosen et al. (1991) e Chataud et al. (1988), que defendem o emprego de temperaturas médias no preparo de hidrolisados subtilisínicos de caseína. Segundo esses autores, tal procedimento pode, ainda, contribuir para a redução do tempo de hidrólise sem provocar significativa desnaturação da enzima, além de minimizar a contaminação microbiana.

Não foram encontrados na literatura trabalhos abordando o efeito da temperatura da reação sobre o perfil peptídico dos hidrolisados protéicos da farinha de trigo ou de outros cereais submetidos ao processo de remoção de fenilalanina. 


\subsubsection{Efeito da relação $\mathrm{E}: \mathrm{S}$}

Visando a avaliar o efeito da relação E:S sobre o perfil peptídico dos hidrolisados protéicos da farinha de trigo, foram comparados os hidrolisados $\mathrm{H} 7, \mathrm{H} 8$ e H5, para os quais foi empregado a E:S para a pancreatina de $2: 100,3: 100$ e 4:100, respectivamente. Como pode ser observado na Tabela I.2, a vantagem de se utilizar uma menor relação $E$ :S não foi encontrada em nenhum dos dois casos. Assim, ao se comparar $2 \% \operatorname{com} 3 \%$, pode ser notado que, apesar de não ter havido diferenças significativas entre os teores de di-tripeptídeos e de aminoácidos livres, a quantidade de grandes peptídeos foi maior a $2 \%$, indicando, nutricionalmente, um perfil peptídico inferior. Na comparação de $3 \%$ com $4 \%$, os valores obtidos para as quatro frações foram estatisticamente iguais, o que demonstra uma similaridade entre os dois perfis peptídicos, do ponto de vista nutricional.

Não foram encontrados na literatura trabalhos que avaliaram o efeito da relação E:S sobre o perfil peptídico dos hidrolisados protéicos da farinha de trigo ou de outros cereais, após a remoção de fenilalanina.

\subsubsection{Tratamento físico do extrato protéico}

A influência do tratamento físico sobre o perfil peptídico dos hidrolisados protéicos de farinha de trigo foi avaliada, comparando-se os resultados obtidos para os hidrolisados $\mathrm{H} 8$ (sem tratamento) e H9 (emprego de ultraturrax). Uma ligeira vantagem da utilização do ultraturrax no preparo do hidrolisado, do ponto de vista nutricional, pode ser observada na Tabela I.2, sendo esta relacionada ao menor teor de grandes peptídeos, visto que a diferença entre os valores obtidos com o emprego do ultraturrax foi de apenas 2,88\% (19,38\% em H8 e 16,50\% em H9).

Não foram encontrados na literatura outros trabalhos que avaliaram o efeito do tratamento físico do extrato sobre o perfil peptídico dos hidrolisados protéicos de farinha de trigo ou de outros cereais, após a remoção de fenilalanina.

\section{CONCLUSÃO}

A caracterização do perfil peptídico de hidrolisados protéicos de farinha de trigo, após a remoção de Phe, estudando o efeito de vários parâmetros hidrolíticos e do tratamento da amostra por ultraturrax, revelou que foi possível obter teores relativamente elevados de di-tripeptídeos $(23,58 \%)$ e de aminoácidos livres (36\%), assim como pequenas quantidades de grandes peptídeos (12\%). Esses resultados foram obtidos ao se utilizar a pancreatina $(E: S=4: 100)$ por 3h 30min, seguida da ação do $\mathrm{EB}(\mathrm{E}: \mathrm{S}=10: 100)$ por 1h 30min, nas condições ótimas de $\mathrm{pH}$ e temperatura de cada enzima.

\section{AGRADECIMENTOS}

Os autores agradecem à CAPES, ao CNPq e à FAPEMIG, pelo apoio financeiro.

\section{REFERÊNCIAS}

AKIYAMA, H.; SAKATA, K.; YOSHIOKA, Y.; MURATA, Y.; ISHIHARA, Y.; TESHIMA, R.; SAWADA, J.; MAITANI, T. Profile Analysis and Immunoglobulin e Reactivity of Wheat Protein Hydrolysates. International Archives Allergy and Immunology, Basel, v. 140, p. 36-42, 2006.

ARROYO-REYNA, A.; HERNÁNDEZ-ARANA, A. The thermal denaturation os stem bromelain is consistent with an irreversible two-state model. Biochimica Biophysica Acta, v. 1248, p. 123-128, 1995.

BARBOSA, C.M.S.; MORAIS, H.A.; DELVIVO, F.M.; MANSUR, H.S.; OLIVEIRA, M.C.; SILVESTRE, M.P.C. Papain hydrolysates of casein: molecular weight profile and encapsulation in lipospheres. Journal of the Science of Food Agriculture, Londres, v. 84, n. 4, p. 1891-1900, 2004.

BOZA, J.J.; MOËNNOZ, D.; VUICHOUD, J.; JARRET, A.R.; GAUDARD-DE-WECK, D.; BALLÈVRE, O. Protein hydrolysate vs free amino acid-based diets on the nutritional recovery of the starved rat. European Journal of Nutrition, v. 39 , p. $237-243,2000$.

CAPOBIANGO, M.; LOPES, D.C.F.; CARREIRA, R.L. ; AFONSO, W.O.; SEGALL, S.D.; SILVESTRE, M.P.C. Optimization of enzyme assisted processes for extracting and hydrolysing corn proteins aiming phenylalanine removal. International Journal of Food Engineering, Berkeley, v. 3, p. 1-19, 2007. 
CARREIRA, R.L.; DE MARCO, L.M.; DIAS, D.R.; MORAIS, H.A.; ORNELLAS, C.B.D.; SILVESTRE, M.P.C. Analysis of peptide profiles of casein hydrolysates prepared with pepsin, trypsin and subtilisin. Acta Farmaceutica Bonaerense, Buenos Aires, v. 23, n. 1, p. 17-25, 2004.

CHATAUD, J. ; DESREUMEUX, S. ; CARTWRIGHT, T. Procédé de fabrication d'un hydrolysat enzymatique de protéines riche en di- et tri-peptides, utilisable notamment en nutrition artificielle et en dietétique. Laboratório Roger Bellon, Neuilly-sur-Seine-FR. A23J3/00. FR87402837.6, 0.274946A1. 14/12/1987, 20/07/1988.

CHICÓN, R.; BELLOQUE, J.; ALONSO, E.; LÓPEZFANDIÑO, R. Antibody binding and functional properties of whey protein hydrolysates obtained under high pressure. Food Hydrocolloids, Oxford, v. 23, p. 593-599, 2009.

DAVIS, M.T.; LEE, T.D. Analysis of peptide mixtures by capillary high performance liquid chromatography: A practical guide to small-scale separations. Protein Science, Nova Iorque, v. 1, p. 935-944, 1992.

FRENHANI, P.B.; BURINI, R.B. Mecanismos de absorção de aminoácidos e oligopeptídeos. Arquivos Gastroenterologia, São Paulo, v. 36, n. 4, p. 227-237, 1999.

GOLOVCHENKO, N.; KATAEVA, I.A.; AKIMENKO, V.K. Analysis of $\mathrm{pH}$-dependent protein interactions with gel filtration medium. Journal of Chromatography, Amsterdã, v. 591, n. 4, p. 121-128, 1992.

GONZÁLEZ-TELLO, P.; CAMACHO, F.; JURADO, E.; PÁEZ, M.P.; GUADIX, E.M. Enzymatic hydrolysis of whey proteins. II. Molecular - weight range. Biotechnology \& Bioengineering, Nova Iorque, v. 44, n. 4, p. 529-532, 1994.

GRIMBLE, G.K.; KEOHANE, P.P.; HIGGINS, B.E.; KAMINSKI Jr., M.V.; SILK, D.B.A. Effect of peptide chain length on amino acid and nitrogen absorption from two lactoalbumin hydrolysates in the normal human jejunum. Clinical Science, Londres, v. 71, n. 1, p. 65-69, 1986.

ITO, S.; YOSHIOKA, S.; OGATA, I.; YAMASHITA, E.; NAGAI, S.; OKUMOTO, T.; ISHII, K.; ITO, M.; KAJI, H.; TAKAO, K.; DEGUCHI, K. Capillary high-performance liquid chromatography/electrospray ion trap time-of-flight mass spectrometry using a novel nanoflow gradient generator. Journal of Chromatography, Amsterdã, v. 1090, p. 178183, 2005.

JE, J.-Y.; QIAN, Z.-J.; BYUN, H.-G.; KIM, S.-K. Purification and characterization of an antioxidant peptide obtained from tuna backbone protein by enzymatic hydrolysis. Process Biochemistry, Londres, v. 42, p. 840-846, 2007.

KAMMOUN, R.; BEJAR, S.; ELLOUZ, R. Protein size distribution and inhibitory effect of wheat hydrolysates on Neutrases. Bioresource Technology, Essex, v. 90, p. 249254, 2003.
KANUFRE, V.C.; SANTOS, J.S.; SOARES, R.D.L.; REIS, D.G. Receitas especiais para fenilcetonúria. Belo Horizonte: Folium, 2001. 65p.

KEOHANE, P.P.; GRIMBLE, G.K.; BROWN, B.; SPILLER, R.C. Influence of protein composition and hydrolysis method on intestinal absorption of protein in man. Gut, v. 26, p. 907-913, 1985.

KONG, X.; ZHOU, H.; QIAN, H. Enzymatic hydrolysis of wheat gluten by proteases and properties of the resulting hydrolysates. Food Chemistry, Londres, v. 102, p. 759763, 2007.

LEMIEUX, L.; PIOT, J.M.; GUILLOCHON, D.; AMIOT, J. Study of the efficiency of a mobile phase used in sizeexclusion HPLC for the separation of peptides from a casein hydrolysate according to their hydrodynamic volume. Journal of Chromatography, Amsterdã, v. 32, p. 499-504, 1991.

LI-JUN, L.; CHUAN-HE, Z.; ZHENG, Z. Analyzing molecular weight distribution of whey protein hydrolysates. Food and Bioproducts Processing, v. 86, n. 1, p. 1-6, 2008.

LOOSEN, P.C.; BRESSPOLLIER, P.R.; JULIEEN, A.R.; PEJOAN, C.H.; VERNEUIL, B. Procede pour preparer um hydrolysat enzymatique. Tessenderlo Cheemie n. v. [BE/ BE]; Stationsstraat, B-3980 Tessenderlo (BE). A23J3/34, C12P21/06 C12S3/14, C07K15/00//A61K37/18, A23J3/04, 3/14. FR-PCT/BE91/00001, W091/10369. 11/01/1991; 25/07/1991.

LOPES, D.C.F.; DELVIVO, F.M.; SILVESTRE, M.P.C. Hydrolysates of skim milk powder: peptide profiles for dietetic purposes. British Food Journal, Bradford, v.107, n.1, p.42-53, 2005.

LOPES, D.C.F.; DELVIVO, F.M.; SILVESTRE, M.P.C. Dietary supplements for phenylketonuria: removing Phe by activated carbon. Nutrition \& Food Science, v. 36 n. 2, p. 96-104, 2006.

LOPES, D.C.F; DELVIVO, F.M.; JANUÁRIO, J.N.; AGUIAR, M.J.B.; STARLING, A.L.P.; SILVESTRE, M.P.C. Phenylalanine removal from whey hydrolysates. Journal of Food Technology, v. 5, n. 2, p. 191-197, 2007.

LOPES, D.C.F.; BIZZOTTO, C.S.; SILVA, V.D.M.; AFONSO, W.O.; LOPES Jr., C.O.; SILVESTRE, M.P.C. Obtention of low-phenylalanine protein hydrolysates from rice: use of two pancreatins. Journal of Food Technology, v. 6 , p. 57-65, 2008.

LOPES Jr., C.O.; AMORIM, A.C.P.; SOUZA, M.W.S.; SILVA, V.D.M.; SILVA, M.R.; SILVESTRE, M.P.C. Efeito de diversos parâmetros na extração protéica do feijão. Acta Scientiarum (UEM), Maringá, no prelo.

LOPEZ-BAJONERO, L.J.; LARA-CALDERON, P.; GALVEZ-MARISCAL, A.; VELASQUEZ-ARELLANO, 
A .; LOPEZ-MUNGUIA, A. Enzimatic production of a low-phenylalanine product from skim milk powder and caseinate. Journal of Food Science, Chicago, v. 56, p. 938-942, 1991.

MANU, B.T.; RAO, U.J.S.P. Influence of size distribution of proteins, thiol and disulfide content in whole wheat flour on rheological and chapati texture of Indian wheat varieties. Food Chemistry, Londres, v. 110, p. 88-95, 2008.

MARTINS, A.M.; FISBERG, R.M.; SCHMIDT, B.J. Fenilcetonúria: abordagem terapêutica NESTLÉ, São Paulo, n. 54, 1993.

McCALLEY, D.V. Effect of buffer on peak shape of peptides in reversed-phase high performance liquid chromatography. Journal of Chromatography A, Amsterdã, v. 1038, p. 77 84, 2004.

MIRA, N.V.M.; MARQUEZ, U.M.L. Importância do diagnóstico e tratamento da fenilcetonúria. Revista de Saúde Pública, São Paulo, v. 34, n. 1, p. 86-96, 2000.

MORAIS, H.A.; DE MARCO, L.M.; OLIVEIRA, M.C.; SILVESTRE, M.P.C. Casein hydrolysates using papain: peptide profile and encapsulation in liposomes. Acta Alimentaria, Budapeste, v. 34, n. 12, p. 59-69, 2005.

MORATO, A.F.; CARREIRA, R.L.; JUNQUEIRA, R.G.; SILVESTRE, M.P.C. Optimization of casein hydrolysis for obtaining high contents of small peptides: use of subtilisin and trypsin. Journal of Food Composition and Analysis, San Diego, v. 13, n. 5, p. 843-857, 2000.

MOSZCZYNSKI, P.; IDZIAK, J. Preparation of enzymatic hydrolysates of casein depleted in phenylalanine. Applied Biochemical Microbiology, Nova Iorque, v. 29, n. 3, p. 302-306, 1993.

NOGUEIRA, R.; LÄMMERHOFER, M.; LINDNER, W. Alternative high-performance liquid chromatographic peptide separation and purification concept using a new mixed-mode reversed-phase/weak anion-exchange type stationary phase. Journal of Chromatography A, Amsterdã, v. 1089, p. 158-169, 2005.

NUPAD - Núcleo de ações e pesquisas em apoio diagnóstico. Disponível em: < http://www.nupad.medicina. ufmg.br/>. Acesso em: 15 de outubro de 2008.

OUTINEN, M.T.; TOSSAVAINEN, O.; HARJU, M.; LINKO, P. Method for removing phenylalanine from proteinaceous compositions, a product so obtained and use thereof. Valio Oy, Helsink, Finland, Patents US 5547687, aug. 20. 1996.

PIMENTEL-GOMES, F. Curso de estatística experimental. 14 ed. Piracicaba, 2000. 477p.

RERAT, A.A. Nutritional supply of proteins and absorption of their hydrolysis products: consequences on metabolism. Proceedings of the Nutrition Society, v. 52, p. 335-344,
1993.

SAINT-SAUVEURA, D.; GAUTHIERA, BOUTINB, S.F.Y.; MONTONIA, A. Immunomodulating properties of a whey protein isolate, its enzymatic digest and peptide fractions. International Dairy Journal, Barking, v. 18, p. 260-270, 2008.

SCHMIDT, D.G.; POLL, J.K. Enzymatic hydrolysis of whey proteins. Hydrolysis of $\alpha$-lactoalbumin and $\beta$-lactoglobulin in buffer solutions by proteolytic enzymes. Netherlands Milk and Dairy Journal, Amsterdã, v. 45, n. 4, p. 225-240, 1991.

SILVA, V.D.M.; MARCO, L.M.; AFONSO, W.O.; LOPES, D.C.F.; JANUÁRIO, J.N.; AGUIAR, M.J.B.; STARLING, A.L.P.; SILVESTRE, M.P.C. Preparation of low-phenylalanine whey hydrolysates, using papain and pancreatin immobilized on activated carbon and alumina. American Journal of Food Technology, Nova Iorque, v. 2, p. 327-341, 2007.

SILVESTRE, M.P.C.; HAMON, M.; YVON, M. Analyses of protein hydrolysates. 1. Use of poly (2-hydroxyethylaspartamide)-silica column in size-exclusion chromatography for the fracionation of casein hidrolysates. Journal of Agricultural and Food Chemistry, Easton, v. 42, p. 27782782, 1994a.

SILVESTRE, M.P.C.; HAMON, M.; YVON, M. Analyses of protein hydrolysates. 2. Characterization of casein hydrolysates by a rapid peptide quantification method. Journal of Agricultural and Food Chemistry, Easton, v. 42, p. 2783-2789, 1994b.

SILVESTRE, M.P.C.; VIEIRA, C.R.; SILVA, M.R.; SILVA, M.C.; LOPES Jr., C.O.; SILVA, V.D.M. Use of an enzymatic process for extracting and hydrolyzing rice proteins aiming at phenylalanine removal. International Journal of Food Engineering, Berkeley, v. 5, n. 1, 2009.

SOARES, R.D.L.; BIASUTTI, E.A.R.; CAPOBIANGO, M.; VIEIRA, C.R.; SILVA, V.D.M.; JANUÁRIO, J.N.; AGUIAR, M.J.B.; SILVESTRE, M.P.C. Preparation of enzymatic skim milk hydrolysates with low phenylalanine content. Acta Farmaceutica Bonaerense, Buenos Aires, v. 25, n. 3, p. 325-332, 2006.

SOARES, R.D.L.; CAPOBIANGO, M.; BIASUTTI, E.A.R; SILVESTRE, M.P.C. Enzime-catalyzed production of oligopeptides from skim milk. Food Biotechnology, Nova Iorque, v. 21, n. 1, p. 45-56, 2007.

SOUZA, M.W.S.; BIASUTTI, E.A.R.; CARREIRA, R.L.; AFONSO, W.O.; SILVA, V.D.M.; SILVESTRE, M.P.C. Obtaining oligopeptides from whey: use of subtilisin and pancreatian. American Journal of Food Technology, Nova Iorque, v. 3, p. 315-324, 2008.

VISSER, S.; SLAGEN, C.J.; ROBBEN, A.J.P.M. 
Determination of molecular mass distributions of whey protein hydrolysates by high-performance size-exclusion chromatography. Journal of Chromatography, Amsterdã, v. 599, p. 205-209, 1992.

WANG, J.; ZHAO, M.; JIANG, Y. Effects of Wheat Gluten Hydrolysate and Its Ultrafiltration Fractions on Dough Properties and Bread Quality. Food Technology and Biotechnology, v. 45, p. 410-414, 2007. 